\title{
SUBJETIVAÇÃO DOS MÉDICOS CUBANOS: DIFERENCIAIS DO INTERNACIONALISMO DE CUBA NO PROGRAMA MAIS MÉDICOS
}

\author{
SUBJECTIVATION OF CUBAN DOCTORS: DISTINGUISHING TRAITS OF CUBA'S \\ INTERNATIONALISM WITHIN THE MORE DOCTORS PROGRAM
}

SUBJETIVACIÓN DE LOS MÉDICOS CUBANOS: VENTAJAS DEL

INTERNACIONALISMO DE CUBA EN EL PROGRAMA MAIS MÉDICOS

\author{
Luciano Bezerra Gomes \\ Emerson Elias Merhy ${ }^{2}$ \\ Alcindo Antônio Ferla ${ }^{3}$
}

Resumo Para compreender certos efeitos do Programa Mais Médicos, estudamos os processos de subjetivação que operaram na constituição dos médicos cubanos ao longo do processo revolucionário desencadeado desde o final da década de 1950. Para tanto, analisamos diversas publicações e consideramos nossas experiências com esses profissionais, usando as formulações de Michel Foucault sobre como as relações de poder-saber constituem os indivíduos, na conexão entre os aspectos políticos e os processos éticos. Evidenciamos o papel que o sistema público de saúde tem na Revolução Cubana, identificando a centralidade dos médicos nesse processo; discutimos os aspectos morais que incidem na constituição ética dos médicos cubanos, especialmente a figura do revolucionário e as práticas de internacionalismo solidário. Por fim, analisamos as transformações recentes naquele país e suas consequências ainda indefinidas sobre a subjetivação dos médicos cubanos.

Palavras-chave médicos; prática profissional; sistemas de saúde; Cuba.
Abstract In order to understand certain effects of the More Doctors Program (Programa Mais Médicos, in Portuguese), we studied the subjectivation processes that occurred in the constitution of the Cuban doctors throughout the revolutionary process triggered ever since the end of the 1950s. To do so, we analyzed many publications, and considered our experiences with these professionals using Michel Foucault's formulations about how the power-knowledge relationships constitute the individuals, in the connection between political aspects and ethical processes. We demonstrate the role that the public health system has in the Cuban Revolution, identifying the centrality of the doctors in this process; we discuss the moral aspects that have an impact on the ethical constitution of the Cuban doctors, especially the figure of the revolutionary and the practices of solidary internationalism. Lastly, we analyze the recent transformations in that country and their yet undefined consequences for the subjectivation of the Cuban doctors.

Keywords physicians; professional practice; health systems; Cuba. 


\section{Introdução}

Em 2013, o governo brasileiro lançou o Programa Mais Médicos (PMM), o qual, entre outras finalidades, permitiu que profissionais brasileiros e estrangeiros atuassem nas equipes de atenção básica que não tinham médicos, vinculando-os a curso de especialização mediante bolsa de estudos. A prioridade da provisão emergencial foi para regiões pobres, de baixa densidade demográfica ou periferias dos grandes centros urbanos. O programa também buscava incrementar o número de médicos no país expandindo vagas de graduação e residência médica (Brasil, 2013; Oliveira et al., 2015).

O PMM sofreu grande resistência das entidades médicas brasileiras, que tentaram inviabilizá-lo nas esferas políticas, jurídicas e perante a opinião pública. Tais movimentos de resistência, entretanto, não foram suficientes, visto o programa ter sido legitimado: pelo Congresso Nacional, que aprovou lei que o regulamenta; pelo Poder Judiciário, que negou diversas representações contra o programa; pela população, que tem apresentado elevados índices de aprovação do PMM (Gomes e Merhy, 2017; Campos e Pereira Júnior, 2016; Santos, Costa e Girardi, 2015). O programa tornou-se referência relevante na organização do sistema de saúde brasileiro de tal forma que foi objeto de formulações pelos candidatos de todos os partidos que disputaram as eleições para a Presidência da República em 2015 (Ferla et al., 2017).

Este artigo é resultado de parte de uma pesquisa de doutorado realizada na linha de pesquisa Micropolítica do Trabalho e o Cuidado em Saúde do Programa de Pós-Graduação em Clínica Médica da Faculdade de Medicina da Universidade Federal do Rio de Janeiro, no período de 2012 a 2016 (Gomes, 2016). Na tese, analisamos a atuação política contemporânea da categoria médica brasileira, o que demandou, entre outros aspectos, debruçarmo-nos sobre as críticas e ações dos médicos brasileiros relacionadas ao PMM. Como a resistência, nos primeiros momentos, se concentrou muito sobre a vinda de médicos cubanos para o Brasil, esse aspecto demandou um olhar específico naquela pesquisa.

Há uma lacuna na produção acadêmica brasileira em relação às singularidades da conformação dos médicos cubanos - que são muito distintas daquelas dos brasileiros -, a qual a forte presença de médicos cubanos no escopo do PMM demanda que seja preenchida. Em revisão que realizamos na base de dados da SciELO Brasil, buscando artigos com os termos 'Cuba' e 'saúde', ou 'Cuba' e 'médicos', ao analisarmos seus títulos e resumos, identificamos que poucos estudavam as especificidades do sistema de saúde cubano (Lourenço e Ruiz, 2014; Osa, 2011; Chaple, 2006).

De 2015 ao início de 2017, foram publicadas diversas pesquisas sobre os impactos do PMM. A quase totalidade se dedicou a analisar a implemen- 
tação do programa em diversas localidades, seus efeitos sobre a distribuição de médicos no país, sobre o escopo de práticas e a produção dos serviços, os indicadores de saúde, a satisfação dos usuários, entre outros aspectos (Facchini et al., 2016).

Entretanto, embora tenha apresentado grande relevância no programa, pouco se identifica sobre as especificidades da atuação dos médicos cubanos. Em artigo sobre as conquistas e os limites do programa, Campos e Pereira Júnior afirmam que "tem sido grande a influência destes profissionais no cotidiano da Atenção Básica brasileira, principalmente por adotarem um padrão de responsabilidade sanitária que lhes tem propiciado construir vínculo e interação com usuários" (Campos e Pereira Júnior, 2016, p. 2.659), mas não avançam numa reflexão sobre as especificidades da atuação deles. Em tese de doutorado defendida em dezembro de 2016, na qual se dedicou a analisar a produção de vínculos entre os médicos cubanos e seus usuários no PMM, o autor reflete sobre o cuidado na atenção básica, sem se aprofundar nas singularidades do ser médico cubano (Garcia Júnior, 2016).

Encontramos um artigo que busca analisar a experiência dos médicos cubanos, afirmando que a "subjetivação da realidade por esses atores sociais constituem ( sic) nosso objeto de estudo" (Terra et al., 2016, p. 2.826). Os autores afirmam que encontraram, como aspectos relevantes na subjetivação dos médicos cubanos atuando no PMM, a presença de "uma cultura de classe distinta da hegemônica no Brasil, uma visão da medicina como realização de vida e altruísmo profissional, a percepção de estranhamento do outro para consigo e uma forma de fazer a Clínica sem negar a Biomedicina mas a incorporando num projeto humanista de saúde" (Terra et al., 2016, p. 2.833). Outro artigo em que se avalia a percepção dos médicos cubanos sobre sua atuação no PMM também indica que esses profissionais têm uma vocação internacionalista e que a solidariedade com outros países é constitutiva de sua formação médica (Silva et al., 2017). Entretanto, por terem analisado apenas a atuação deles no Brasil, sem promover uma conexão com os processos históricos de sua formação como categoria profissional, consideramos que essas publicações não apresentam adequadamente as especificidades da constituição dos processos de subjetivação que operaram na formação dos médicos cubanos e do papel que eles desempenham em seu país.

Avaliamos que, para podermos compreender melhor os efeitos da presença dos médicos no PMM, bem como os efeitos em dobra do PMM nesses profissionais, precisamos conhecer melhor esses atores. Para tanto, se faz necessária uma análise voltada para os processos sociais que incidiram em sua subjetivação. Por isso, estudamos os processos que levaram à atual configuração dos médicos cubanos, objetivo de nossa pesquisa, e acreditamos ser como 
uma primeira contribuição para esse debate na produção acadêmica recente do Brasil que elaboramos este artigo.

\section{Materiais e métodos}

Por opção, mas também pela falta de outras pesquisas com objetivo similar que pudessem servir de apoio e contraponto às ideias formuladas em nosso estudo, decidimos elaborar o presente artigo na forma de um ensaio teórico. Para tanto, foram-nos fundamentais as indicações de Adorno, para quem "o ensaio procede, por assim dizer, metodicamente sem método" (Adorno, 2012, p. 30). Nesse caminho, Adorno destaca a necessidade da interação de conceitos na experiência intelectual, de modo que não se avança em um sentido único e num continuum, mas a densidade da articulação dos conceitos é que define a potência do pensamento formulado.

Nesse sentido, coletamos materiais que permitissem apreender o modo como os médicos cubanos vêm se inserindo naquela sociedade e no mundo, vendo sua constituição como parte do processo revolucionário vigente desde a década de 1950. Tomamos preferencialmente as publicações divulgadas naquele país que permitissem identificar a maneira como se produzem e reproduzem as suas concepções. Assim, acessamos diversos livros que circulam apenas lá e que adquirimos em várias livrarias da ilha que vendem obras para os turistas e em outras que vendem livros para os próprios cubanos. Também procuramos referências com vários médicos e professores de medicina cubanos com quem nos relacionamos.

Ao longo da pesquisa, algumas fontes evidenciaram-se como mais relevantes: narrativas publicadas por médicos que participaram do processo revolucionário cubano na Sierra Maestra e nos primeiros anos do governo; registros de médicos cubanos mediante experiências vivenciadas em outros países, como Bolívia, Venezuela e Paquistão; documentos que orientam a organização do sistema de saúde cubano; produções de pensadores relevantes da experiência cubana, especialmente que atuaram no processo revolucionário, como Ernesto Che Guevara; publicações que tentam reconstruir as lutas do povo cubano ou a vida dos que eles consideram seus heróis. Vale salientar que os próprios autores cubanos que se debruçam sobre a análise dos fundamentos políticos e ideológicos da saúde pública cubana indicam os discursos que Fidel Castro proferiu nas últimas décadas como uma das fontes mais relevantes para se compreender a construção da saúde naquele país (Ochoa, 2009), o que nos indicou a necessidade de um olhar diferenciado para tal fonte.

Além desses materiais, acessamos livros publicados no Brasil que analisam diversos aspectos políticos da vida ou especificamente da saúde em Cuba. Assistimos ainda a vídeos documentários sobre a Revolução Cubana, 
a trajetória dos seus ícones, a vida na ilha e seus dilemas políticos, os quais foram considerados também como 'textos' na pesquisa.

O manejo de tal material permitiu desenvolver uma pesquisa de natureza qualitativa, de nível exploratório e caráter analítico (Gil, 1999). Todos esses materiais passaram por leitura na íntegra, sendo identificados aqueles que apresentavam aspectos mais relevantes, os quais passaram por posterior leitura em profundidade, tendo sido elaborados fichamentos que foram organizados logicamente para permitir a análise temática e a redação do artigo (Gil, 2002; Eco, 2001).

Mas consideramos que o ensaio também se alimenta da experiência, mediada pela própria organização conceitual à qual ela se conecta (Adorno, 2012), e este aspecto foi por nós trabalhado. Sabendo que vivemos, por diversos motivos, um momento de rarefação e empobrecimento da experiência, defendemos a ideia de que o saber germinado desses processos deve ser reconhecido e encontrar formas de ser validado (Benjamin, 2012; Bondía, 2002). Assim, parte do alimento do presente artigo está nas experiências que seus autores tiveram com os médicos cubanos, de diferentes formas; para tanto, analisamos as afecções que se produziram em nós (Rolnik, 2006) em nossos encontros com os cubanos, em Cuba e no Brasil. Em diversos momentos, atuamos com eles, especialmente nas mais de 120 horas de formação sobre atenção básica ofertada a várias dezenas deles por um dos autores deste artigo, nos cursos de acolhimento realizados pelo PMM em mais de uma oportunidade em Cuba e também no Brasil, entre 2013 e 2017. Também atuamos com eles nas atividades de campo de ensino e pesquisa realizadas cotidianamente pelos autores em contato com sistemas e serviços de saúde, nas quais o programa e as questões relacionadas à organização do trabalho na saúde foram acumulando registros e ideias para essa produção. Nesses momentos, conversamos especificamente sobre sua atuação profissional e as comparamos ao trabalho médico no Brasil. Além disso, por diversos motivos, em épocas distintas, viajamos àquela ilha, onde observamos vários aspectos da subjetivação operante lá e sobre os quais tentamos elaborar uma compreensão. Nesses momentos, pudemos: conhecer algumas universidades onde se formam os médicos cubanos e conversar com vários de seus professores; trabalhar na Unidade Central de Cooperação Médica e fazer uma visita guiada em seu museu das missões internacionalistas de cooperação cubana na saúde; reunirmo-nos com autoridades governamentais cubanas do setor saúde e com médicos e gestores brasileiros que também participavam das atividades lá; visitar serviços de saúde destinados ao atendimento de cubanos e outros voltados a turistas; participar de atos cívicos e comemorativos; hospedarmo-nos não só em Havana, mas também em cidades menores, como Guantánamo e Trinidad, alojando-nos em hotéis e casas de cubanos que hospedam estrangeiros, entre outros contatos que 
nos permitiram interagir com pessoas que tinham diferentes concepções e experimentar várias formas de se viver em Cuba. As nossas percepções desencadeadas com base nessas vivências foram registradas em diários, os quais serviram de bússola para orientar a análise, e processadas mediante incontáveis sessões de conversa entre os autores, bem como nas diversas escritas e reescritas que o texto sofreu.

Analisamos todos esses materiais refletindo sobre as disputas em torno da redefinição do poder médico. Nesse sentido, buscamos compreender o modo como os médicos cubanos se constituem como sujeitos políticos no atual contexto. Para tanto, foram importantes as formulações de Michel Foucault sobre as novas biopolíticas: sua concepção sobre o poder; os modos de governar as pessoas como eixo para compreensão das estratégias de poder-saber contemporâneas; a constituição dos sujeitos como objeto da política, em torno da ética como constituição de si (Foucault, 1984, 1987, 1988, 2008a, 2008b, 2010a, 2010b). Com tais fontes e conceitos, analisamos o processo de subjetivação que operou na constituição do médico cubano, entendendo como se inventaram seus valores - de certa forma, colocando em análise o valor desses valores (Foucault, 2004a).

O estudo aqui apresentado, pela sua natureza, não demandou apreciação por um comitê de ética em pesquisa. Um dos pesquisadores contou com o apoio de bolsa de doutorado da Coordenação de Aperfeiçoamento de Pessoal de Nível Superior (Capes). A pesquisa também é parte de um conjunto maior de estudos que visam produzir uma genealogia do Programa Mais Médicos, vinculados ao Observatório de Políticas e Cuidados em Saúde, cuja estruturação contou com financiamento do Conselho Nacional de Desenvolvimento Científico e Tecnológico (CNPq), de acordo com o processo n. 405045/2013.

\section{Resultados}

Embora reconheçamos que a Revolução Cubana transformou aquele país em várias dimensões e elas têm inter-relações, como focamos nos médicos cubanos, descreveremos brevemente o sistema de saúde implementado lá após 1959, enfatizando as mudanças na formação médica, as missões internacionalistas cubanas e os efeitos da crise que se instala a partir da década de 1990.

\section{O sistema de saúde e a atuação dos médicos em Cuba}

Diversos indicadores apontam o impacto da Revolução Cubana na saúde, e o reconhecimento dos seus avanços nessa área é um dos aspectos mais enfatizados pelos que a defendem - até seus adversários, embora a contragosto, 
tendem a reconhecer esse aspecto. Um exemplo disso se viu em pleno 'período especial', termo com que os cubanos denominam o momento em que se implementaram transformações relevantes na ilha, como abertura ao turismo e composição público-privada em certas áreas da economia, visando superar a grave crise econômica e social que lá se seguiu à queda do bloco soviético. Pois mesmo no 'período especial' ainda se identificam avanços na saúde pública cubana, tais como a queda da mortalidade infantil de 11,1 por mil nascidos vivos, em 1989, para 6,4 por mil nascidos vivos, em 1999 (Lamrani, 2011; Navarro, 2009; Castro, 2007; Ramonet, 2006).

Para conseguir tais efeitos, Cuba deu atenção diferenciada à formação de trabalhadores da saúde, especialmente aos médicos. Dos cerca de seis mil médicos que havia antes da Revolução, apenas 1.400 trabalhavam nos serviços públicos, quase todos em Havana. Com as migrações ocorridas logo após 1959, restaram cerca de três mil médicos no país. O então presidente, Fidel Castro, caracterizou essa fuga como "muy inmoral. Ese es un crimen contra el pueblo, contra el enfermo, contra el infeliz, contra el que sufre" (Castro, 2007, p. 126). A evasão foi mais intensa entre os professores de medicina: dos 157 existentes na Faculdade de Medicina de Havana, a única do país até então, apenas 16 ainda estavam lá em 1962. E foi a partir dos que ficaram que eles formaram massivamente novos médicos, valorando que "los hombres que en medio de una sociedad de corrupción y de egoísmo permanecieron puros, pueden servir de semilla y de maestros" (Castro, 2007, p. 127). Em 1999, quatro décadas depois da implantação da Revolução, atuavam lá 64.863 médicos - um para cada 175 habitantes -, 29.984 destes atuavam como médicos de Medicina General Integral (MGI), especialistas que atuam na atenção primária. Entre 1960 e 2004, formaram-se na ilha 85.887 médicos (Lamrani, 2011; Castro, 2007).

Entretanto, além do incremento numérico, a aposta era formar profissionais com uma nova concepção política, próximos aos valores preconizados pela Revolução: mais que tecnicamente competentes, que fossem capazes de colaborar com a construção de uma sociedade de iguais. Para tanto, promoveram mudanças na formação, com intensificação das atividades práticas e inserção nos seis anos do curso em todos os estabelecimentos de saúde. No campo tecnológico (Mendes-Gonçalves, 1994), a medicina comunitária orientou a reorganização do sistema de saúde, ofertando atenção médica integral nos territórios, com participação ativa das pessoas (Navarro, 2009). A atenção especializada foi ampliada e descentralizada, mas articulada à atuação dos MGIs. Para os cubanos, a opção por tal modelo se dava por um "gran propósito: ir pasando de la medicina terapéutica a la preventiva" (Castro, 2007, p. 133).

\section{O internacionalismo na saúde}


Cerca de meio milhão de cubanos já colaboraram voluntariamente em missões internacionalistas nas mais variadas áreas: educação, desporto, militar, entre outras. Para eles, esse tipo de desprendimento não seria possível em sociedades capitalistas desenvolvidas (Castro, 2007, 2016).

Na saúde, desde a primeira missão, em 1962, até o ano de 2011, cerca de 132 mil cubanos participaram em missões de solidariedade em mais de cem países. Mais de 85 milhões de pessoas já foram atendidas por esses profissionais. Em 2011, 31 mil médicos cubanos atuaram gratuitamente em 69 países. No primeiro ano de trabalho da missão cubana no Haiti, em algumas áreas se reduziu a mortalidade infantil de 42 para 16 por mil nascidos vivos. Atuando em algumas regiões da África, no período de um ano, diminuíram a mortalidade infantil de noventa para trinta por mil nascidos vivos (Lamrani, 2011; Castro, 2007).

$\mathrm{O}$ atendimento a pessoas em situações de desastres ambientais e crises humanitárias com recursos e profissionais cubanos (mesmo em países sem relações comerciais com Cuba por decorrência da Revolução Cubana) é apenas parte dessa colaboração (Guadalupe, 2011). As missões tentam, progressivamente, oferecer apoios estruturantes: além da presença prolongada em alguns lugares, têm formado médicos desses países, seja implantando lá escolas médicas com a participação dos cubanos, seja levando-os para estudar em Cuba (Castro, 2007).

Nos anos 1980, Cuba chegou a ter 24 mil estudantes estrangeiros na ilha. No 'período especial', embora esse número tenha se reduzido, em 1999 criou-se a Escola Latino-Americana de Ciências Médicas (Elam), que já formou dezenas de milhares de médicos de mais de 120 países (Lamrani, 2011).

A atenção à população e as missões humanitárias na saúde foram sempre custeadas por recursos cubanos. Entretanto, a crise financeira tem ampliado o esforço para manutenção da gratuidade da atenção aos cubanos. Não obstante muitas missões internacionalistas continuem às expensas de Cuba, nos últimos anos algumas iniciativas foram realizadas com pagamento dos países apoiados destinado a profissionais e governo cubano.

Para melhorar a gestão desse processo, no final de 2011 Cuba criou a empresa estatal 'Comercializadora de Servicios Médicos Cubanos S.A.' (SMC). Embora tenha como missão "fomentar las relaciones de cooperación en la esfera de la salud entre Cuba y el mundo" (Comercializadora de Servicios Médicos Cubanos, 2013), a SMC visava angariar recursos para seu próprio sistema de saúde. Com essa empresa, Cuba institucionalizaria ações para: cobrar pela assistência médica eventual a estrangeiros na ilha, a trabalho ou a turismo, por meio de planos individuais ou institucionais; realizar, na ilha, tratamentos médicos a estrangeiros, mediante pagamento; arrecadar financiamentos para parcerias no campo da pesquisa; cobrar a estrangeiros para realizarem gradu- 
ação e pós-graduação nas escolas de saúde cubanas; promover atendimento de médicos cubanos em outros países.

A vinda ao Brasil de médicos cubanos no PMM foi viabilizada pela SMC.

\section{Discussão}

Muito se enfatiza, nas análises sobre as sociedades socialistas, os aspectos repressivos relacionados ao stalinismo, às relações disciplinares e à rede de poderes que promove o controle das pessoas. Sem desconhecer a relevância dessas técnicas ou seus efeitos no contexto cubano, tentamos evidenciar outros aspectos das práticas que se desencadearam em Cuba. Destacamos que concordamos com Foucault quando ele diz: "se quisermos analisar a genealogia do sujeito na civilização ocidental, é preciso considerar não apenas as técnicas de dominação, mas também as técnicas de si. Devemos mostrar a interação que se produz entre os dois tipos de técnicas" (Foucault, 2010b, p. 95). Os processos de subjetivação estão associados às duas técnicas e se manifestam, com efeitos diversos, em todas as civilizações e culturas, sendo oportuna a análise que descreve as relações entre o Estado e a sociedade civil. Aqui abordamos cinco dimensões que analisam as estratégias de produção de processos de subjetivação utilizadas desde a Revolução Cubana em relação à formação e às práticas médicas.

\section{Organizações para a mobilização subjetiva da população}

Os dirigentes revolucionários cubanos sempre promoveram instituições que aliavam disciplina e estímulo à autonomia. Os focos guerrilheiros precisavam se guiar pelas linhas gerais do movimento, tendo estrutura militar ao mesmo tempo que deviam tomar iniciativas autônomas em numerosas ocasiões. Nessa direção, assim como os vietcongues, repuseram as teorias organizacionais que se baseavam no modelo do exército ultrarrígido da fase napoleônica, abrindo desenhos de organizações com grandes espaços para as autodecisões. Ao assumirem o governo, tiveram que mudar as instituições existentes e, ao mesmo tempo, formar novos revolucionários tendo por base a grande maioria da população que os apoiava, mas que não tinha participado da 'escola' da luta armada. Assim, promoveram amplas mobilizações sociais e criaram instituições com um caráter pedagógico e subjetivo, as organizações de massa, que seriam as principais instâncias de democracia na ilha (Castro, 2007), em clara tensão entre controle e autonomia. As relações entre as instituições e a produção de cultura para ordenar padrões de hegemonia dos modos de pro- 
dução na sociedade não é invenção cubana, sendo aquelas com efeitos mais visíveis o aparato educacional, o aparelho jurídico-legal e as políticas sociais, de maneira mais geral, e as formas de articular a cultura com as coletividades - assim como a análise da formação e do trabalho médicos como prática social inserida no conjunto de valores da sociedade (Donnangelo e Pereira, 1976).

No caso de Cuba, no período posterior a 1959, se destacaram: os comitês de defesa da Revolução; as milícias nacionais revolucionárias; as várias organizações revolucionárias que se unificaram para formar o Partido Comunista de Cuba; a Federação das Mulheres Cubanas; a Associação de Jovens Rebeldes, que se tornaria a União de Jovens Comunistas; a Federação Estudantil Universitária; a Central de Trabalhadores de Cuba; e a Associação Nacional de Pequenos Agricultores (Navarro, 2009).

Essas entidades, porém, não seriam tão relevantes se não estivessem articuladas a toda uma estratégia complementar de constituir um sujeito moral no campo da política: o 'revolucionário'.

\section{Do'revolucionário' como sujeito moral}

Para Fidel Castro, o líder tem que ser uma referência moral para sua própria população, para ser legítimo porta-voz de seus anseios e conduzir as ações coletivas perante seu próprio povo e as outras nações (Comandante, 2003; Un día com Fidel, 1987). Em seus discursos, percebe-se como as missões internacionalistas de solidariedade também se integram nessa concepção, sendo vistas como uma das ações que reforçam a envergadura moral cubana ante os demais países (Castro, 2007, 2016).

A preocupação com a ética do revolucionário é relevante no pensamento de Fidel Castro, seja para 'despertar' o revolucionário dentro das pessoas, seja como elemento organizacional da política. Ao analisar sua luta guerrilheira, ele afirma que "nos preocupávamos em implantar uma ética" (Ramonet, 2006, p. 193). Ou ainda: “eu penso muito sobre o papel da ética. Qual é a ética de um revolucionário? Todo pensamento revolucionário começa por um pouco de ética" (Ramonet, 2006, p. 520). Ele destaca que “o primeiro dever de um revolucionário é ser extremamente rigoroso consigo mesmo" (Ramonet, 2006, p. 518).

Um lugar diferenciado é reservado aos que foram capazes de dedicar sua vida à revolução, como Camilo Cienfuegos e Che Guevara (Martínez, 2012; Navarro, 2009). No entanto, constrói-se a noção de que qualquer pessoa poderia seguir os nobres princípios revolucionários. Assim, todos seriam potencialmente revolucionários e precisariam se desenvolver adequadamente, de modo a assimilar os valores e desempenhar papéis revolucionários a todo momento (Castro, 2007; Ramonet, 2006). 
É por isso que, periodicamente, certas pessoas são elevadas ao lugar de heróis. Uma evidência disso são os cinco espiões cubanos que foram presos nos Estados Unidos, por desenvolver contraespionagem junto aos grupos anticastristas de Miami, para evitar atentados terroristas em Cuba (Morais, 2011) - papel em que também foram colocados pelas autoridades norte-americanas, uma vez que foram suas características pessoais e seu objeto de atuação que os tornaram perigosos e até ameaçadores ao regime vigente no país norte-americano.

Entre as referências, a figura mais forte na construção subjetiva do médico na perspectiva cubana é, provavelmente, Che Guevara (Ortiz, 2012).

\section{Do 'guerrilheiro heroico'}

Che Guevara tornou-se modelo para as estratégias cubanas de indução de práticas éticas em torno da moral do revolucionário. Além de um homem de ação, Guevara foi um importante pensador das experiências em que se envolvia, ofertando elementos para o debate teórico e para a construção de estratégias políticas mais complexas. O próprio Fidel colaborou para a construção da figura mítica do Che, falando sempre de suas qualidades como modelo de revolucionário, governante, militante e pessoa (Ramonet, 2006).

Assim, conhecer suas ideias ajuda a compreender as disputas éticas em Cuba. Segundo Besancenot e Löwy (2009), o pensamento de Guevara não é dogmático, e sua aposta na dimensão ética do comunismo é uma contribuição original ao marxismo. Para Che, era fundamental a constituição de um novo homem, do revolucionário. Segundo ele, uma revolução, “esse cambio social tan profundo demanda, también, cambios en la contextura mental de las gentes" (Guevara, 2011, p. 121), postura esta que não é estranha a outros marxistas, como Gramsci.

Guevara afirma que “debe crearse un nuevo tipo humano. Y si cada uno es el arquitecto propio de esse nuevo tipo humano, mucho más fácil será para todos el crearlo y el que sea el expoente de la nueva Cuba" (Guevara, 2011, p. 120). Ele apostava que todos os homens, caso se dedicassem intensamente a processos coletivos, poderiam se constituir como 'legítimos' revolucionários.

Para Guevara, entretanto, esse processo não deveria ficar ao encargo de cada indivíduo: o socialismo precisaria estimular essa reconstrução subjetiva, de modo distinto da constituição dos valores e do processo ético na sociedade capitalista. Ele, então, desenvolveu a concepção de que o próprio futuro do socialismo demandaria o desenvolvimento de um 'novo homem', mediante processos distintos de subjetivação.

Esse 'novo homem', ou melhor, esse quadro revolucionário, deveria ser identificado com base em suas ações e não apenas por seus discursos. Além de ações pontuais, toda a vida deveria ser dedicada ao processo revolucionário: 
Guevara via a entrega total à Revolução como valor fundamental (Guevara, 2011), movimento próximo a uma ascese, uma prática de si (Foucault, 1985, 2010a).

Para Che, o comunista deveria se dedicar ao estudo em todos os níveis, ser criativo, lutar contra a enfermidade do sectarismo e dedicar-se à construção da nova sociedade e do novo homem. Enfatizava: a produção de novas relações com o trabalho, para que ele seja criador e fonte de novas emoções; a promoção de novas relações com os homens de todos os países. Enfim, segundo o líder cubano, o revolucionário deveria ser guiado por grandes sentimentos de amor (Guevara, 2011).

\section{Do médico cubano como 'revolucionário'}

Tomemos, agora, o modo como esses processos incidiram sobre os médicos cubanos. Quanto ao modelo tecnológico (Mendes-Gonçalves, 1994), o deslocamento dos aspectos curativos para uma lógica preventiva não representou uma ruptura com a medicalização nem com a perspectiva biomédica. Pelo contrário, eles tentam garantir "la creación de las condiciones no solo para combatir las enfermedades, sino para prevenirlas. Porque en el futuro tendremos cada dia más médicos, y cada día menos enfermos" (Castro, 2007, p. 133). Esta concepção, além de ancorada numa nova nosopolítica da medicina moderna normalizando os corpos e as populações, atualiza mitos da extinção das doenças pela definição médica de modos saudáveis de se viver e de se governarem as cidades (Foucault, 2004b, 2011).

Entretanto, identifica-se um diferencial na construção subjetiva do médico como ator revolucionário, dimensão central na política cubana. A dimensão ética dos médicos cubanos foi sempre campo de embates fundamentais. A figura de Ernesto Guevara como referência na construção subjetiva do 'revolucionário' incide ainda mais fortemente quando se refere aos médicos cubanos (Fulgueiras, 2013). Até hoje se distribuem biografias e coletâneas de seus textos aos alunos de medicina. Usando a terminologia de Guevara, os médicos são vistos em Cuba como quadros técnico-científicos (Guevara, 2011) e, desse modo, de acordo também com a concepção moral (Foucault, 1984, 2010b) delineada por Che.

Ao discursar para estudantes de medicina em Cuba, Guevara descreveu o médico como um trabalhador que deveria se aproximar do povo e compreender profundamente o objeto de seu trabalho. Assim, além de estar nos serviços de saúde, o médico teria que participar da dinâmica de vida das pessoas a quem ele atende. Considerava, porém, que eles não deveriam se aproximar do povo com a intenção de fazer caridade, e sim com a prática da solidariedade (Guevara, 2011). 
Enfim, só se conseguiria ser, realmente, um médico revolucionário caso se estivesse participando ativamente de uma revolução. Não se é revolucionário sozinho, sem um contexto, sem um movimento revolucionário do qual se participe e com o qual contribua diretamente. Só assim é que “ya entonces tenemos el derecho y hasta el deber de ser, por sobre todas las cosas, un médico revolucionario, es decir, un hombre que utiliza los conocimientos técnicos de su profesión al servicio de la Revolución y del pueblo" (Guevara, 2011, p. 119). E esses 'quadros' deveriam realizar uma medicina revolucionária onde fosse preciso, onde houvesse pessoas em sofrimento. Aqui, Che alinhava as missões internacionalistas à construção subjetiva do médico revolucionário, tal atitude sendo valorada como um elemento de honra e comparada à glória heroica. Para Guevara, o internacionalismo seria, simultaneamente, um imperativo estratégico na luta contra o imperialismo e uma alta exigência moral (Guevara, 2011; Lamrani, 2011; Besancenot e Löwy, 2009; Saab, 2006).

A própria Elam, além do incremento de médicos nos países pobres, segundo Fidel, visava 'exportar' esse modelo de médico, buscando “crear una nueva concepción, una nueva doctrina de cuál debe ser el papel del médico en la sociedad, porque en las capitales y en las ciudades grandes de América Latina existen médicos de sobra, pero no han sido educados todos en la idea de cuál debe ser el deber de un médico" (Castro, 2007, p. 25). Ao discursar na Elam, Fidel reforçou que: "lo importante que debe aportar esta escuela es el ejemplo de lo que debe y puede ser un médico educado en princípios humanitarios" (Castro, 2007, p. 153).

Foucault considera que toda moral comporta tanto os códigos de comportamento como determinados modos de subjetivação. Certas morais são 'orientadas para o código', com a ênfase no sujeito submetendo-se a um conjunto de leis a que deve seguir; em outras ocasiões, entretanto, encontraríamos morais 'orientadas para a ética', cujo polo dinâmico está nos processos de subjetivação e nas práticas de si, em que é mais importante o investimento em certos modos de o indivíduo se constituir a si mesmo como sujeito de verdade do que a acepção a um conjunto de valores determinados. As relações entre essas duas morais são dinâmicas, e Foucault destaca que a ocorrência de mudanças na política modifica as relações éticas dos sujeitos consigo mesmos (Foucault, 1984, 1985). Pelo exposto, podemos identificar, em Cuba, muitos aspectos de uma moral 'orientada para o código'. Todavia, consideramos que predominaria lá uma ênfase na 'determinação da substância ética' dos processos de subjetivação, que operam de modo que os indivíduos se constituam como sujeito moral de suas ações em torno do modelo do 'revolucionário' - caracterizando uma sociedade cujo vetor mais forte estaria na construção de certas práticas de si, mediadas por instituições e dinâmicas coletivas, consolidando o padrão de uma moral 'orientada para a ética'. 


\section{Releitura liberal do médico cubano}

A análise do modelo cubano é complexa por apresentar caráter híbrido. Por um lado, esse modelo disciplinaria a população integrando-a a instituições que fomentam a atuação das pessoas na vida social, estimulam solidariedade interna e externa e promovem o 'revolucionário' como sujeito moral da política. Por outro, Cuba opera com conceitos da subjetivação neoliberal - o que se evidencia na ênfase na teoria do capital humano, do Homo oeconomicus (Foucault, 2008b), na reorganização atual da sociedade cubana.

Em vários discursos, Fidel utilizava a concepção de 'capital humano' como elemento de análise e de luta social (Castro, 2007). Cremos que isso se deu, em primeiro lugar, por uma questão econômica, pois seria uma possibilidade de inserção mais potente de Cuba numa economia mundial cuja hegemonia se deslocava para o trabalho imaterial (Lazzarato e Negri, 2001). Também, provavelmente, seria uma tentativa de usar as ferramentas do opositor contra ele mesmo, diante das urgências do 'período especial'. Essas duas motivações, no final, seriam faces indissociáveis de uma mesma moeda. Tais apostas ficavam patentes quando Fidel valorizava a contribuição do 'capital humano' cubano para a superação das dificuldades econômicas e para manter as vitórias conseguidas no socialismo. Ele defendia ainda a ideia de que: "viveremos do capital humano. Com esse capital humano podemos ajudar muitos, com nossa experiência podemos ajudar muitos, e com essa experiência podemos ajudar a nós mesmos" (Ramonet, 2006, p. 541).

Poder-se-ia argumentar que Fidel tentava cunhar uma noção de capital humano desvinculada da concepção liberal. Entretanto, um conceito não opera desconectado de outros que lhe fazem vizinhança, que se relacionam e atuam integrados num certo espectro, agindo num determinado contexto, numa geofilosofia (Deleuze e Guattari, 1997). Parece-nos que, ao tentarem fazer a subversão da teoria do capital humano e apostar na capacidade de instituir um Homo oeconomicus de outra ordem, os cubanos caíram na armadilha que Ernesto Guevara havia apontado, ao afirmar que as 'armas sujas do capitalismo' não serviriam para construir o socialismo (Guevara, 2011).

Acreditamos ter demonstrado que Cuba tentou articular: a moral como motor do sujeito político; o internacionalismo solidário na constituição do modelo moral do herói revolucionário; a teoria do capital humano. Isso como parte de uma estratégia de governo que buscou manter a disputa da subjetivação socialista ante as aberturas econômicas realizadas no 'período especial'.

Na saúde, tal perspectiva era explícita quando Fidel afirmava: "estamos lutando para criar o melhor capital médico do mundo" (Ramonet, 2006, p. 472). E teve consequências práticas relevantes: a integração ao sistema de saúde de uma empresa que comercializa a assistência médica para estrangei- 
ros e que realiza missões internacionalistas não apenas de solidariedade, mas também de prestação 'comercial' de serviços médicos.

No início dos anos 2000, Fidel afirmava que a gratuidade da atenção à saúde em Cuba deveria ser para os que vivem e trabalham lá. Mas que, em algum tempo, seria possível que pessoas fossem à ilha se tratar nos seus prestigiosos centros de saúde, considerando até que "no hay quién lo pueda hacerlo mejor, ni más económicamente" (Castro, 2007, p. 206-207). Sabermos isso nos permitiu compreendermos, em janeiro de 2017, uma propaganda, no desembarque do aeroporto de Havana, em que se estimulavam os turistas a irem realizar cirurgias plásticas naquela ilha.

Não criticamos a existência de interesses econômicos em uma sociedade que se afirma socialista; tentamos é analisar as implicações dessa estratégia, apontando para uma inflexão na subjetivação que se vinha construindo na ilha. Tais efeitos se dão, por exemplo, no elemento internacionalista da construção subjetiva da figura moral do 'revolucionário'. Ao lado da solidariedade como ação estratégica e valor moral (Castro, 2016), passa a incidir também uma negociação que visa ao retorno financeiro, colocando nas regras de mercado o que antes era valor inerente ao revolucionário. Remetemo-nos a Marx e Engels (2010), para quem uma das brutalidades do capital era justamente transformar tudo em mercadoria, mesmo aquilo relacionado à honra e aos valores mais relevantes das pessoas.

Estabelece-se um processo de subjetivação distinto quando o médico que suportará a distância, atuando em outros países, terá como recompensa uma melhoria financeira pessoal ou mesmo a manutenção da assistência gratuita que seus parentes e conterrâneos terão. Não a aposta em outro ideal de mundo, e sim um sacrifício em prol da manutenção de um certo padrão de vida pessoal e para a população cubana. Sinais disso foram captados no Brasil entre participantes do PMM (Silva et al., 2017; Terra et al., 2016).

Essa transformação incide não apenas na subjetivação dos médicos. O motivo de orgulho com que Cuba justificava certa atuação política nos organismos internacionais, denunciando as atitudes de países capitalistas, passa também, a partir de tal deslocamento, a ser usado como divulgação para captar mais recursos, praticamente na mesma forma do marketing das indústrias capitalistas. É o que se identifica, por exemplo, quando vemos as menções honrosas que receberam as missões cubanas de solidariedade na saúde sendo utilizadas como material de divulgação institucional sobre a qualidade dos profissionais cujos serviços estão, agora, a ser ofertados mediante pagamento (Comercializadora de Servicios Médicos Cubanos, 2013).

Quando se busca expandir fronteiras comerciais com outros países, é possível imaginar que o receio político de se realizarem parcerias com o governo cubano não deve ser um impedimento para o avanço dos serviços da SMC. Quando os médicos cubanos foram proibidos de solidariamente salvar vidas 
em New Orleans após a passagem do furacão Katrina, pelo receio estadunidense de que eles aproveitassem a entrada no país para realizar atos políticos, Fidel assegurou: "nuestros médicos tienen la instrucción rigurosa de atenerse, por encima de todo, a una regla: No hablar jamás de política, ni de religión, ni de filosofia" (Castro, 2007, p. 35). E essa atitude foi efetivamente identificada entre os profissionais do PMM (Terra et al., 2016; Garcia Júnior, 2016). Tal garantia, transposta para um contexto comercial, tranquilizaria os países que desejassem fazer parcerias para terem profissionais capazes de realizar atendimento médico eficaz, segundo as concepções biomédicas atuais, barato e sem maiores riscos políticos.

Essas são algumas das tensões que se evidenciam na estratégia de se induzir economicamente a lógica do capital humano e, ao mesmo tempo, uma ascese da solidariedade com todos os povos do mundo.

\section{Considerações finais}

A maneira como as pessoas foram mobilizadas, o modo como os valores foram construídos, com os mais variados processos de subjetivação operando intensamente, de maneira a constituir uma usina a céu aberto para se fabricarem novos sujeitos 'revolucionários', tudo isso aponta para o desenvolvimento de uma subjetivação singular a operar em Cuba, no contexto das articulações entre o Estado e a sociedade e a medicina e a sociedade. Pelo que demonstramos, consideramos que o médico cubano representou uma das figuras centrais daquele processo, e aparentemente ainda se constituirá como tal.

Esperamos, enfim, ter tornado mais compreensíveis as singularidades do ser médico cubano e, assim, ajudado para a realização de outros estudos sobre a atuação desses profissionais no âmbito do PMM.

\section{Colaboradores}

Luciano Bezerra Gomes realizou a pesquisa de doutorado e redigiu este artigo que dela deriva. Emerson Elias Merhy orientou a pesquisa de doutorado e a elaboração deste artigo, participando de todas as etapas da pesquisa e da redação do artigo. Alcindo Antônio Ferla revisou a pesquisa de doutorado e a redação deste artigo, agregando reflexões e referenciais à versão inicialmente elaborada. 
Resumen Para comprender ciertos efectos del Programa Mais Médicos (Más Médicos), estudiamos los procesos de subjetivación que intervinieron en la constitución de los médicos cubanos a lo largo del proceso revolucionario desencadenado desde finales de la década de 1950. Para esto, analizamos diversas publicaciones y consideramos nuestras experiencias con estos profesionales usando las formulaciones de Michel Foucault respecto a cómo las relaciones de poder-saber constituyen los individuos, en la conexión entre los aspectos políticos y los procesos éticos. Pusimos en evidencia el papel que juega el sistema público de salud en la Revolución Cubana, identificando el rol central de los médicos en dicho proceso; discutimos los aspectos morales que inciden en la constitución ética de los médicos cubanos, especialmente la figura del revo $\neg$ lucionario y las prácticas de internacionalismo solidario. Para finalizar, analizamos las transformaciones recientes en ese país y sus consecuencias aún indefinidas sobre la subjetivación de los médicos cubanos.

Palabras clave médicos; ejercicio profesional; sistemas de salud; Cuba.

\section{Notas}

${ }^{1}$ UniversidadeFederal daParaíba, CentrodeCiências Médicas, DepartamentodePromoçãodaSaúde, . João Pessoa, Paraíba, Brasil

$<$ lucianobgomes@gmail.com>

Correspondência: Universidade Federal da Paraíba, Centro de Ciências Médicas, Departamento de Promoção da Saúde, Cidade Universitária, CEP 58051-900, João Pessoa, Paraíba, Brasil.

${ }^{2}$ UniversidadeFederaldo Rio de Janeiro, Centro deCiências daSaúde, Macaé, Rio de Janeiro, Brasil. <emerhy@gmail.com>

${ }^{3}$ Universidade Federal do Rio Grande do Sul, Escola de Enfermagem, Programa de Pós-Graduação em Saúde Coletiva, Porto Alegre, Rio Grande do Sul, Brasil.

$<$ ferlaalcindo@gmail.com>

\section{Referências}

ADORNO, Theodor W. Notas de literatura I. 2. ed. São Paulo: Duas Cidades; Editora 34, 2012.

BENJAMIN, Walter. Magia e técnica, arte e política: ensaios sobre literatura e história da cultura. 8. ed. rev. São Paulo: Brasiliense, 2012.

BESANCENOT, Olivier; LÖWY, Michael. Che Guevara: uma chama que continua ardendo. São Paulo: Editora Unesp, 2009.

BONDÍA, Jorge L. Notas sobre a experiência e o saber de experiência. Revista Brasileira de Educação, Rio de Janeiro, n. 19, p. 20-28, abr. 2002. Disponível em: < http://www.scielo. br/scielo.php?script=sci_arttext\&pid=S141324782002000100003\&lng =en \&nrm=iso > . Acesso em: 30 ago. 2017.

BRASIL. Presidência da República. Casa Civil. Subchefia para Assuntos Jurídicos. Lei federal n. 12.871, de 22 de outubro de 2013. Institui o Programa Mais Médicos, altera as leis n. 8.745, de 9 de dezembro de 1993, e n. 6.932, de 7 de julho de 1981, e dá outras providências. Disponível em: <http://www.planalto.gov. br/ccivil_03/_ato2011-2014/2013/lei/112871. htm> Acesso em: 29 de maio de 2018. 
CAMPOS, Gastão W. S.; PEREIRA JÚNIOR, Nilton. A atenção primária e o Programa Mais Médicos do Sistema Único de Saúde: conquistas e limites. Ciência \& Saúde Coletiva, Rio de Janeiro, v. 21, n. 9, p. 2.655-2.663, set. 2016. Disponível em: <http://www.scielo.br/ scielo.php?script $=$ sci_arttext\&pid $=$ S1413$81232016000902655 \& \operatorname{lng}=\mathrm{en} \& \mathrm{nrm}=\mathrm{iso}>$. Acesso em: 30 ago. 2017.

CASTRO, Fidel. Generosos defensores de la vida. La Habana: Editora Política, 2007.

CASTRO, Fidel. Solidariedad sin fronteras. Compiladores: Hugo Rius, Mirta Muñiz, Disamis Arcia. La Habana: Ocean Sur, Instituto Cubano de Amistad con los Pueblos, 2016.

CHAPLE, Enrique B. La salud pública en Cuba y su experiencia internacional (19592005). História, Ciências, Saúde: Manguinhos, Rio de Janeiro, v. 13, n. 3, p. 709-716, set. 2006. Disponível em: <http://www.scielo. br/scielo.php?script=sci_arttext\&pid=S0104$59702006000300008 \& \operatorname{lng}=\mathrm{en} \& \mathrm{nrm}=\mathrm{iso}>$. Acesso em: 30 ago. 2017.

COMANDANTE. Direção de Oliver Stone. Documentário produzido em 2003 com base em entrevistas gravadas no ano de 2002. Disponível em: <https://www.youtube.com/play list?list=PLD0FFD0F96D9E3072 > Acesso em: 29 de maio de 2018.

COMERCIALIZADORA DE SERVICIOS MÉDICOS CUBANOS. Website. Disponível em: <http:// www.smcsalud.cu/smc $>$. Acesso em: 29 maio 2018.

DELEUZE, Gilles; GUATTARI, Félix. o que é a filosofia. 2. ed. Rio de Janeiro: Editora 34, 1997.

DONNANGELO, Maria C. F.; PEREIRA, Luiz. Saúde e sociedade. São Paulo: Duas Cidades, 1976.

ECO, Umberto. Como se faz uma tese. 17. ed. São Paulo: Perspectiva, 2001.
FACCHINI, Luiz A. et al. O Programa Mais Médicos: análises e perspectivas. Ciência \& Saúde Coletiva, Rio de Janeiro, v. 21, n. 9, p. 2652-2652. Set. 2016. Disponível em: $<$ http://www.scielo.br/scielo.php?script=sci arttext\&pid=S1413-81232016000902652\&lng =pt\&nrm=iso >. Acesso em: 30 ago. 2017.

FERLA, Antônio A. et al. Ideias, imagens e crenças na produção de políticas públicas: o caso do Programa Mais Médicos. Interface: Comunicação, Saúde, Educação, Botucatu, v. 21, supl. 1, p. 1.129-1.141, 2017.

FOUCAULT, Michel. História da sexualidade 2: o uso dos prazeres. Rio de Janeiro: Edições Graal, 1984.

FOUCAULT, Michel. História da sexualidade 3: o cuidado de si. Tradução de Maria Thereza da Costa Albuquerque; revisão técnica de José Augusto Guilhon de Albuquerque. Rio de Janeiro: Edições Graal, 1985.

FOUCAULT, Michel. Vigiar e punir: nascimento da prisão. Petrópolis: Vozes, 1987.

FOUCAULT, Michel. História da sexualidade I: a vontade de saber. Rio de Janeiro: Edições Graal, 1988.

FOUCAULT, Michel. Microfísica do poder. 20. ed. Rio de Janeiro: Edições Graal, 2004a.

FOUCAULT, Michel. O nascimento da clínica. 6. ed. Rio de Janeiro: Forense Universitária, 2004 b.

FOUCAULT, Michel. Segurança, território, população: curso dado no Collège de France (1977-1978). São Paulo: Martins Fontes, 2008a.

FOUCAULT, Michel. Nascimento da biopolitica: curso dado no Collège de France (1978-1979). São Paulo: Martins Fontes, 2008b.

FOUCAULT, Michel. Hermenêutica do sujeito: curso dado no Collège de France (1981-1982). 3. ed. São Paulo: WMF Martins Fontes, 2010a. 
FOUCAULT, Michel. Ética, sexualidade, politica. 2. ed. Rio de Janeiro: Forense Universitária, $2010 \mathrm{~b}$.

FOUCAULT, Michel. Arte, epistemologia, filosofia e história da medicina. Rio de Janeiro: Forense Universitária, 2011.

FULGUEIRAS, José A. El Che se viste de blanco: cronicas bolivianas. La Habana: Pablo de la Torriente Editorial, 2013.

GARCIA JÚNIOR, Carlos A. S. Médicos cubanos e usuários do Sistema Único de Saúde: análise da produção de vínculos a partir do Programa 'Mais Médicos'. 2016. 334 fls. Tese (Doutorado em Ciências Humanas) - Programa de Pós-Graduação Interdisciplinar em Ciências Humanas, Centro de Filosofia e Ciências Humanas, Universidade Federal de Santa Catarina, Florianópolis, 2016.

GIL, Antonio C. Métodos e técnicas de pesquisa social. 5. ed. São Paulo: Atlas, 1999.

GIL, Antonio C. Como elaborar projetos de pesquisa. 4. ed. São Paulo: Atlas, 2002.

GOMES, Luciano B. A atual configuração politica dos médicos brasileiros: uma análise da atuação das entidades médicas nacionais e do movimento médico que operou por fora delas. 298 fls. Tese (Doutorado em Medicina) - Programa de Pós-Graduação em Clínica Médica, Faculdade de Medicina, Universidade Federal do Rio de Janeiro, Rio de Janeiro, 2016.

GOMES, Luciano B.; MERHY, Emerson E. Uma análise da luta das entidades médicas brasileiras diante do Programa Mais Médicos. Interface: Comunicação, Saúde, Educação, Botucatu, v. 21, supl. 1, p. 1.103-1.114, 2017. Disponível em: <http://www.scielo.br/ scielo.php?script $=$ sci_arttext $\&$ pid $=$ S1414$32832017005014101 \& \operatorname{lng}=\mathrm{en} \& \mathrm{nrm}=\mathrm{iso}>$. Acesso em: 22 nov. 2017.

GUADALUPE, Luis E. R. Fidel Castro ante los desastres naturales: pensamiento e acción. La Habana: Oficina de Publicaciones del Consejo de Estado, 2011.
GUEVARA, Ernesto. Che Guevara presente, antologia minima. La Habana: Editorial de Ciencias Socialis, 2011.

LAMRANI, Salim. Cuba, lo que nunca le dirán los medios. La Habana: Editorial José Marti, 2011.

LAZZARATO, Maurizio; NEGRI Antonio. Trabalho imaterial: formas de vida e produção de subjetividade. Rio de Janeiro: DP\&A, 2001.

LOURENÇO, Edvânia A. S.; RUIZ, Reina F. La política de salud en Cuba en el nuevo milenio: la contribución del trabajo social. Revista Katálysis, Florianópolis, v. 17, n. 2, p. 207-217, dez. 2014. Disponível em: <http://www.scielo. br/scielo.php?script=sci_arttext\&pid=S141449802014000200207\&lng =en \&nrm=iso >. Acesso em: 30 ago. 2017.

MARTÍNEZ, Fernando D. Camilo, un huracán de cariño y fuego. La Habana: Casa Editorial Verde Olivo, 2012.

MARX, Karl; ENGELS, Friedrich. Manifesto comunista. 1. ed. revista. São Paulo: Boitempo, 2010.

MENDES-GONÇALVES, Ricardo B. Tecnologia e organização social das práticas de saúde: características tecnológicas de processo de trabalho na rede estadual de centros de saúde de São Paulo. São Paulo: Hucitec; Abrasco, 1994.

MORAIS, Fernando. Os últimos soldados da Guerra Fria. São Paulo: Companhia das Letras, 2011.

NAVARRO, José C. C. Nace una Cuba Nueva (1959-1975). In: NAVARRO, José C. C.; LÉON, Arnaldo S. História de Cuba, 1959-1999: liberación nacional y socialismo. La Habana: Editorial Pueblo y Educación, 2009. p. 1-163.

OCHOA, Francisco R. (org.). Fundamentos politicos ideológicos de la salud pública revolucionaria cubana. La Habana: Ecimed, 2009.

OLIVEIRA, Felipe P. et al. Mais Médicos: um programa brasileiro em uma perspectiva 
internacional. Interface: Comunicação, Saúde, Educação, Botucatu, v. 19, n. 54, p. 623-634, set. 2015. Disponível em: <http://www.scielo. br/scielo.php?script=sci_arttext\&pid $=$ S1414$32832015000300623 \& \operatorname{lng}=\mathrm{en} \& \mathrm{nrm}=\mathrm{iso}>$. Acesso em: 30 ago. 2017.

ORTIZ, Víctor Pérez-Galdós. Che: su palabra como arma de combate. La Habana: Editora Política, 2012.

OSA, José A. Um olhar para a saúde pública cubana. Estudos Avançados, São Paulo, v. 25, n. 72, p. 89-96, ago. 2011. Disponível em: $<$ http://www.scielo.br/scielo.php?script=sci_ arttext\&pid=S0103-40142011000200008\&lng =en \&nrm=iso >. Acesso em: 30 ago. 2017.

RAMONET, Ignacio. Fidel Castro: biografia a duas vozes. São Paulo: Boitempo, 2006.

ROLNIK, Suely. Cartografia sentimental: transformações contemporâneas do desejo. Porto Alegre: Sulina, Editora da UFRGS, 2006.

SAAB, Tarek W. Los niños del infortunio: memórias de la misión médica cubana en Pakistán. La Habana: Ediciones Plaza, 2006.

SANTOS, Leonor M. P.; COSTA, Ana M.; GIRARDI, Sábado N. Programa Mais Médicos: uma ação efetiva para reduzir iniquidades em saúde. Ciência \& Saúde Coletiva, Rio de Janeiro, v. 20, n. 11, p. 3.547-3.552, nov.
2015. Disponível em: <http://www.scielo.br/ scielo.php?script $=$ sci_arttext\&pid $=$ S1413$81232015001103547 \& \operatorname{lng}=\mathrm{en} \& \mathrm{nrm}=$ iso $>$. Acesso em: 30 ago. 2017.

SILVA, Hilton P. et al. O Projeto Mais Médicos para o Brasil: desafios e contribuições à atenção básica na visão dos médicos cooperados. Interface: Comunicação, Saúde, Educação, Botucatu, v. 21, supl. 1, p. 1.257-1.268, 2017.

TERRA, Lilian S. V. et al. Análise da experiência de médicos cubanos numa metrópole brasileira segundo o Método Paideia. Ciência \& Saúde Coletiva, Rio de Janeiro, v. 21, n. 9, p. 2.825-2.836, set. 2016. Disponível em: $<$ http://www.scielo.br/scielo.php?script=sci arttext\&pid=S1413-81232016000902825\&lng =en\&nrm=iso > . Acesso em: 30 ago. 2017.

UN DÍA CON FIDEL. Direção de Gianni Miná. Documentário realizado com base em entrevista gravada em 27 de junho de 1987. DVD.

Recebido em 31/08/2017. Aprovado em 10/12/2017. 